\title{
Layer recombination technique for waterflooded low-permeability reservoirs at high water cut stage
}

\author{
Chuanzhi Cui ${ }^{1} \cdot$ Zhongwei Wu$^{1}$
}

Received: 13 October 2017 / Accepted: 20 January 2018 / Published online: 30 January 2018

(c) The Author(s) 2018. This article is an open access publication

\begin{abstract}
Layer recombination is an important technique to improve the oil recovery of waterflooded low-permeability reservoirs, especially at high water cut stage. This technique significantly increases the oil recovery percent of relatively lower-permeability layers when all the formation layers are perforated and produced simultaneously. Parameters such as formation permeability, crude oil viscosity, remaining oil saturation, the presence of hydraulic fractures or others have an impact on the production performance after layer recombination. It is quite difficult to take all these influencing factors into consideration when making layer recombination decisions. Therefore, this paper proposes the 'apparent mobility' as the decision index of layer recombination for low-permeability reservoirs at high water cut stage, and the optimal apparent mobility contrast values for layer recombination under different producing pressure drop are obtained. The equivalent permeability of fractured layers is introduced into the apparent mobility. This technique has been applied to the layer recombination treatment of Block Five of Bonan oilfield in Shengli oilfield of SINOPEC, and the oil recovery increased approximately $3.1 \%$ compared with the previous commingling production scenario, which confirmed the validity of this proposed method.
\end{abstract}

Keywords Layer recombination · Low-permeability reservoirs · High water cut stage · Apparent mobility contrast · Equivalent permeability

\section{List of symbols}

$Q_{t} \quad$ Liquid flow rate, $\mathrm{cm}^{3} / \mathrm{s}$

$K \quad$ Absolute permeability, $\mu \mathrm{m}^{2}$

A Sectional area, $\mathrm{cm}^{2}$

$\Delta P \quad$ Pressure drop, $10^{-1} \mathrm{MPa}$

$G \quad$ Threshold pressure gradient, $10^{-1} \mathrm{MPa} / \mathrm{cm}$

$M \quad$ Apparent mobility, $\mu \mathrm{m}^{2} / \mathrm{mPa} \mathrm{s}$

$L \quad$ Distance from water well to oil well, $\mathrm{cm}$

$\mu \quad$ Viscosity, $\mathrm{mPa} \mathrm{s}$

\section{Subscripts}

$l \quad$ Liquid phase

$o \quad$ Oil phase

$w \quad$ Water phase

Chuanzhi Cui

ccz2008@126.com

1 College of Petroleum Engineering, China University of Petroleum (East China), Qingdao City, Shandong Province, 266580, People's Republic of China

\section{Introduction}

Low-permeability reservoirs possess poor reservoir physical properties. To improve the productivity and economic profit, commingling production is generally used during early development stage. Different reservoir physical properties of layers lead to different recovery percent of reserves and serious interlayer interferences (Ehlig-Economides and Joseph 1987; Jackson and Banerjee 2000). As an important technique to reduce the interlayer interferences, layer recombination is of important significance to reduce the differences of interlayer recovery percent and increase oil recovery (Shi et al. 2006, Hu et al. 2010; Cui and Zhao 2010).

Layer recombination technique is to combine layers with similar formation physical properties and recovery percent of reserves together during middle and late development and to produce them with one same set of well pattern. Currently, layer recombination of low-permeability reservoirs mainly focuses on static indexes or economic parameters (Chen et al. 2007; Liu et al. 2007; Zhang et al. 2005; Fu et al. 2002). For instance, the principle of layers recombination which is carried out in the Hu7 Nansha Sanzhong reservoir is that the permeability contrast (defined as a ratio of maximum to minimum permeability in the same development

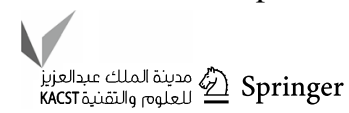


unit) after recombination is less than 10 (Chen et al. 2007). In the research of La-Sa-Xing oilfield, the limit of average interlayer permeability contrast is around 2.5 (Fu et al. 2002). Wang et al. (2007) recombined layers of low-permeability reservoir in Anan oilfield and achieved good effect. Wang and Niu (2004) studied influencing factors of layer recombination of Xin-37 fault block reservoir in Dongxin oilfield. Chen et al. (2007) analyzed permeability contrast limits for layer recombination of serious heterogeneous reservoir during high water cut period. Yu (2010) determined the policy limits of single factors in layer recombination of Chunhua oilfield. For medium- and high-permeability sandstone reservoirs, Cui et al. (2016) introduced the pseudo flow resistance as a decision index of layer recombination, which did not consider the influence of hydraulic fractures and threshold pressure gradient.

During middle and late development period of lowpermeability reservoirs, permeability, effective thickness, crude oil viscosity and oil saturation of every single layer as well as threshold pressure gradient and artificial fractures all will influence the performance of layer recombination. At present, layer recombination is mainly based on static parameters of single layers and does not consider their comprehensive effects. In this paper, influencing factors of layer recombination for low-permeability reservoirs were analyzed. A reasonable decision index involving static parameters and dynamic parameters of single layers as well as artificial fractures was established for layer recombination, and the corresponding policy limit was suggested from some sensitive analysis.

\section{Influencing factors of layer recombination}

Permeability, reservoir thickness, crude oil viscosity, recovery percent of reserves and artificial fractures or their combination will influence the development effect of layer recombination. In this paper, the effects of interlayer permeability contrast, crude oil viscosity contrast and remaining oil saturation contrast as well as artificial fracture on layer recombination were analyzed.

A reservoir numerical simulation model was established based on reservoir parameters of a well group in Block Five of Bonan in Shengli oilfield. The reservoir simulator we adopted in the study is ECLIPSE. This well group, covering an area of $250 \times 250 \mathrm{~m}$, is an inverted five-spot well pattern, including one injection well and four producing wells. The area is divided into $50 \times 50$ grids. It employs co-injection and commingling of two layers with each layer's thickness of $5 \mathrm{~m}$. In the basic model, crude oil viscosity is $1.0 \mathrm{mPa} \mathrm{s}$ and permeability of single layer is $25 \times 10^{-3} \mu \mathrm{m}^{2}$. Figure 1 shows the applied relative permeability curve of Block Five of Bonan in Shengli oilfield. In the process of simulation, BHP control of each well is adopted, and the pressure drawdown is controlled in $10 \mathrm{MPa}$.

\section{Interlayer permeability contrast}

Due to different permeability, the two studying single layers have different recovery percent. In the model, permeability of the first layer is still $25 \times 10^{-3} \mu \mathrm{m}^{2}$ and
Fig. 1 Typical relative permeability curve of low-permeability reservoir

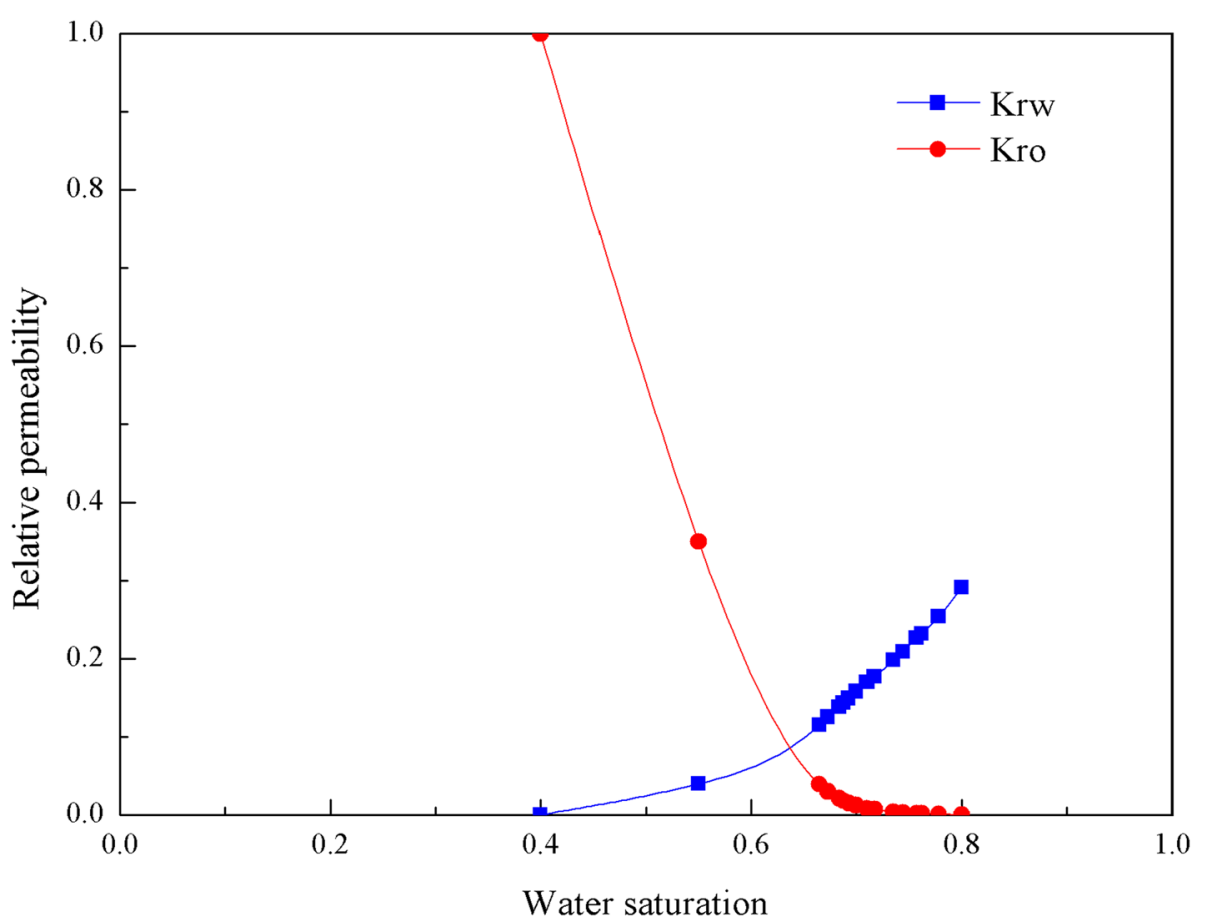


permeability of the second single layer is changed in each case. The recovery percent differences between two layers under $90 \%$ total water cut when the permeability contrast between the first layer and the second layer varies from 2 to 8 are shown in Fig. 2. A proportional relationship between their recovery percent differences and the permeability contrast was observed. When the permeability contrast exceeds 3 , the recovery percent difference intensifies significantly with the further increase in permeability contrast. Therefore, the permeability contrast within a set of development unit shall be limited within 3 during layer recombination.

\section{Interlayer crude oil viscosity contrast}

Different crude oil viscosity will lead to different development effects. In the model, the crude oil viscosity of the second layer is $1.0 \mathrm{mPa}$ s. The recovery percent differences between two studying layers under $90 \%$ total water cut when crude oil viscosity contrast of the two layers varies from 1.5 to 4 are shown in Fig. 3. There is also a proportional relationship between recovery percent differences and crude oil viscosity contrast. When the crude oil viscosity contrast is larger than 2, the recovery percent difference intensifies. Therefore, the crude oil viscosity contrast within a set of development unit shall be smaller than 2 during layer recombination.
Fig. 2 Relation between interlayer recovery percent difference and permeability contrast

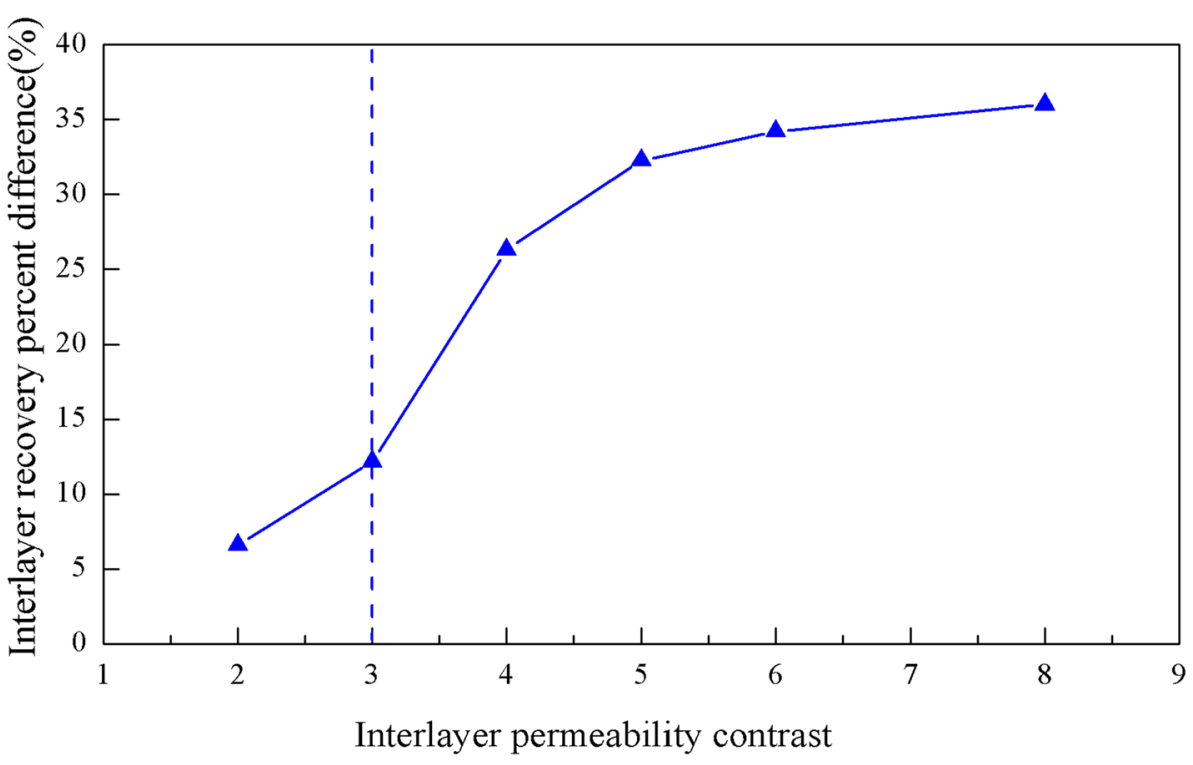

Fig. 3 Relation between interlayer recovery percent difference and oil viscosity contrast

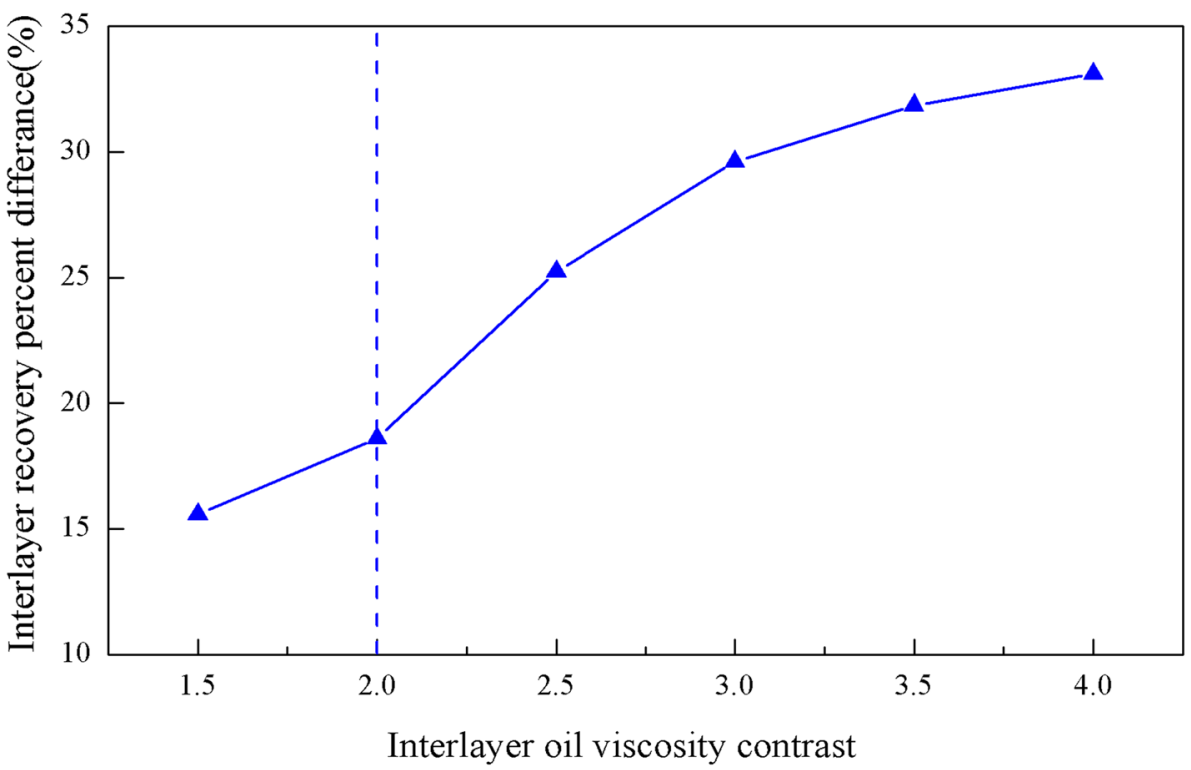

Interlayer oil viscosity contrast 


\section{Remaining oil saturation contrast}

Suppose the remaining oil saturation of first layer at commingling is 0.4 . The recovery percent differences between two studying layers under $90 \%$ total water cut when their remaining oil saturation contrast varies between 1.11 and 1.63 are shown in Fig. 4. It is observed that recovery percent difference is proportional to remaining oil saturation contrast. When remaining oil saturation contrast is higher than 1.24 , the recovery percent difference intensifies significantly. When the remaining oil saturation of first layer at commingling is 0.35 and 0.45 , respectively, the simulated result showed similar rules as shown in Fig. 4. And the results showed that the limit is near 1.24. Therefore, the remaining oil saturation contrast within a set of development unit shall be smaller than 1.24 during layer recombination.

\section{Artificial fractures}

In the development of low-permeability reservoir, artificial fracture is often used to improve permeability of the stratum. To explore the effect of artificial fractures on two-layer commingling effect, a two-layer model was established. Permeability of the first layer was set $50 \times 10^{-3} \mu \mathrm{m}^{2}$, and permeability of the second layer was $5 \times 10^{-3} \mu \mathrm{m}^{2}$. Artificial fractures were employed to the second layer at the injection well. Fractures showed 0.5 penetration ratio and $10 \mu \mathrm{m}^{2} \mathrm{~cm}$ conductivity. Commingling effect using artificial fractures was compared with that without using artificial fractures (Fig. 5). Under two-layer commingling, artificial fracturing of low-permeability layer did not affect the development effect of high-permeability layer, but improved the development effect of low-permeability layer.

\section{Decision index for layer recombination}

\section{The determination of decision index}

The above analysis shows that there are many factors to influence layer recombination. It is difficult to consider all these influencing factors when making layer recombination decision. For the convenience of layer recombination, this paper suggested to use interlayer apparent mobility contrast (defined as a ratio of maximum to minimum apparent mobility in one same development unit) as the basic decision index of layer recombination.

When oil and water flow simultaneously at one way, under consideration of threshold pressure gradient, the liquid production rate can be represented as:

$$
\begin{aligned}
Q_{t} & =K\left(\frac{k_{r o}}{\mu_{o}}+\frac{k_{r w}}{\mu_{w}}\right) A\left(\frac{\Delta p}{L}-G\right) \\
& =K\left(\frac{k_{r o}}{\mu_{o}}+\frac{k_{r w}}{\mu_{w}}\right) A \frac{\Delta p}{L}\left(1-\frac{G}{\Delta p / L}\right)
\end{aligned}
$$

The oil phase permeability and water phase permeability are defined to be:

$k_{o}=K \cdot k_{r o}\left(1-\frac{G}{\Delta p / L}\right)$

$k_{w}=K \cdot k_{r w}\left(1-\frac{G}{\Delta p / L}\right)$

Then Eq. (1) can be rewritten as:

$$
Q_{t}=\left(\frac{k_{o}}{\mu_{o}}+\frac{k_{w}}{\mu_{w}}\right) A \frac{\Delta p}{L}
$$

Fig. 4 Relation between oil recovery percent difference and oil saturation contrast

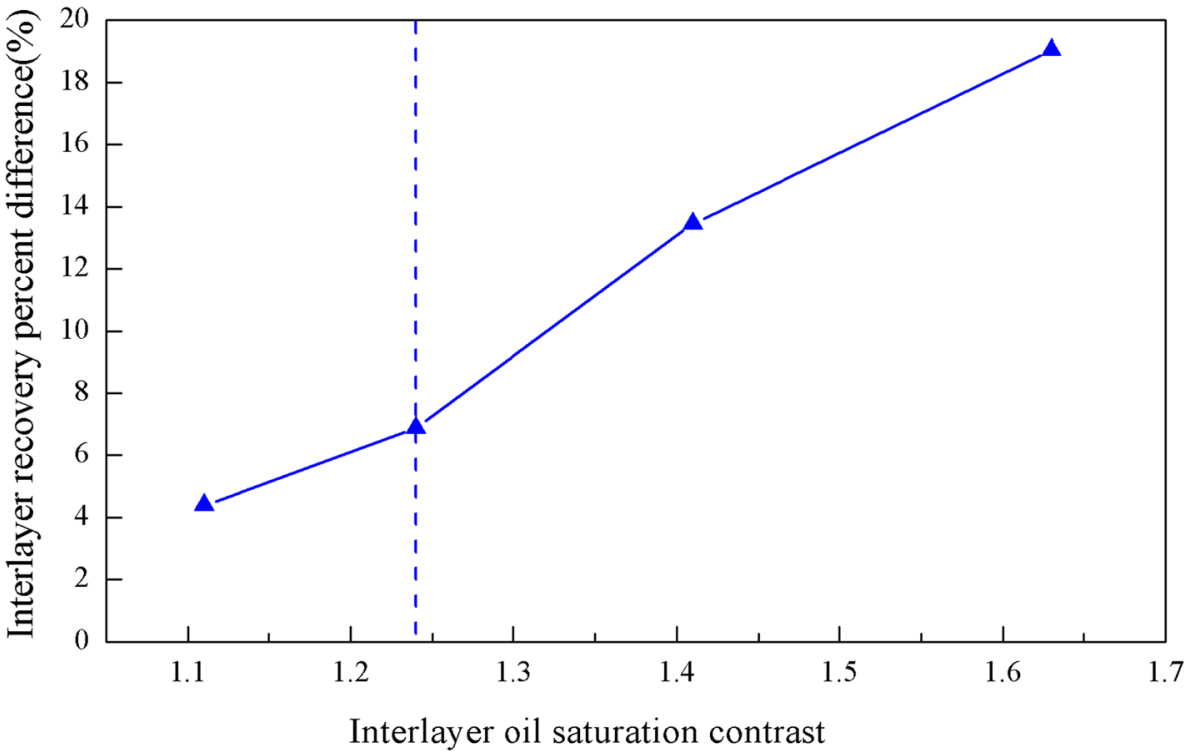

Interlayer oil saturation contrast 
Fig. 5 Oil recovery percent of different layers

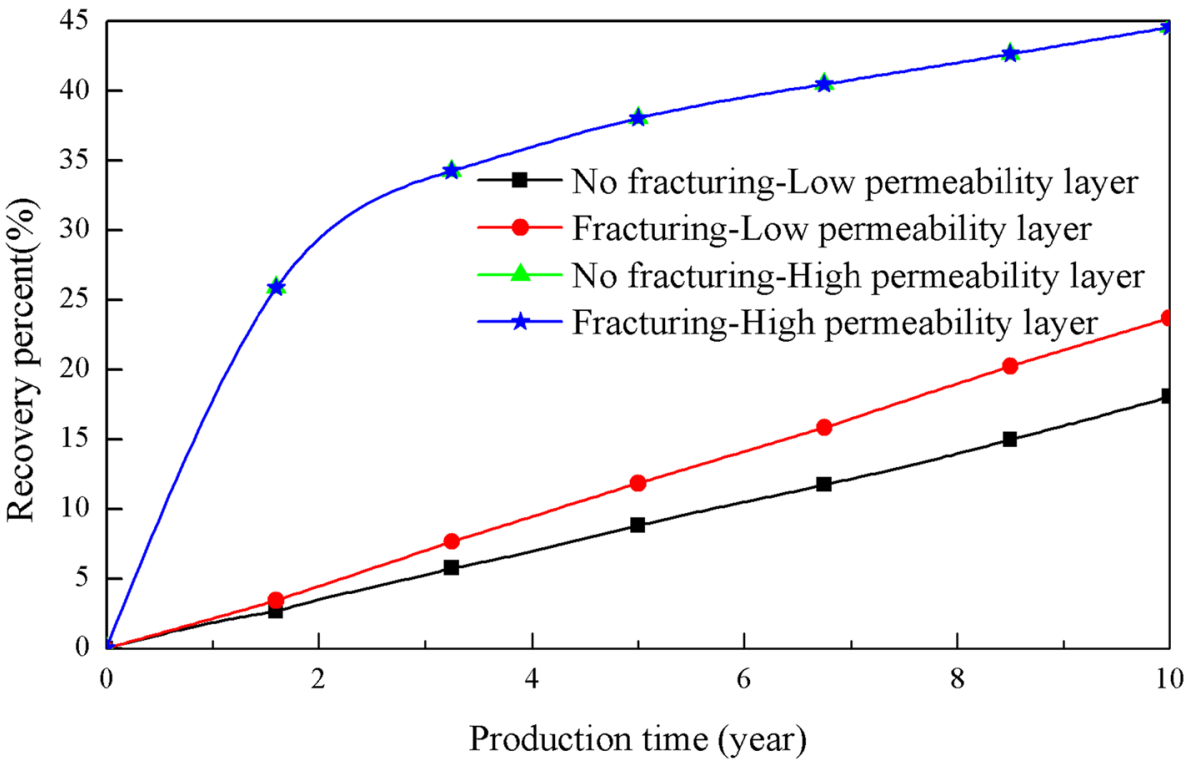

Apparent mobility is defined as:

$M=\frac{k_{o}}{\mu_{o}}+\frac{k_{w}}{\mu_{w}}$

Then the liquid production rate calculation equation becomes:

$Q_{t}=M A \frac{\Delta p}{L}$

Apparent mobility includes permeability, crude oil viscosity, oil saturation, producing pressure drop and threshold pressure gradient. Moreover, effect of hydraulic fracturing on reservoir formations was converted into changes in reservoir permeability and included into the apparent mobility. Therefore, apparent mobility could fully reflect the effect of different indexes on layer recombination.

\section{Equivalent conversion of effect of hydraulic fracturing on reservoir permeability}

A two-layer model was established. When the permeability of the second layer is $1 \times 10^{-3} \mu \mathrm{m}^{2}$, the hydraulic fracturing was employed at this layer and the fracture size is $25 \%$ (here the fracture size is the ratio of the fracture length and the injector-producer distance), and the conductivity of fracture was $10 \mu \mathrm{m}^{2} \mathrm{~cm}$. The permeability of the first layer is set as $5 \times 10^{-3} \mu \mathrm{m}^{2}$. The simulation result showed that the recovery percent of the first layer is higher than the second layer's when the production time is 10 years. Then, the permeability of the first layer is set as $4,3,2.6,2.5$ and $2.3 \times 10^{-3} \mu \mathrm{m}^{2}$, respectively, we got different simulation results. We found when the permeability of the first layer is $2.6 \times 10^{-3} \mu^{2}$, the recovery percent of the first layer is same as the second layer's. Then,
$2.6 \times 10^{-3} \mu \mathrm{m}^{2}$ can be viewed as the equivalent permeability of the low-permeability layer after the low-permeability layer was fractured. This is expressed by permeability contrast of the two layers, that is, the expanded multiples of permeability after hydraulic fracturing of the low-permeability layer. In this case, the expanded multiple of permeability is 2.6. When the permeability of the second layer is 1,5 and $10 \times 10^{-3} \mu^{2}$, respectively, and the fracture sizes are 35, 45, 50, 55, 60, 65 and $75 \%$, respectively, we got the corresponding expanded multiples of permeability with the above same steps. The results are shown in Fig. 6.

It can be seen from Fig. 6 that the expanded multiples of permeability after hydraulic fracturing of the low-permeability layer increase gradually as fracture size increases. Given same fracture size, the expanded multiples of permeability are inversely proportional to permeability.

During the process of layer recombination, the expanded multiples of permeability of layers with artificial fractures could be determined according to its permeability and fracturing size. Equivalent permeability was used to calculate the apparent mobility.

\section{Variation law of apparent mobility}

The recovery percent and interlayer apparent mobility contrast between two studying layers under $90 \%$ total water cut when interlayer permeability contrast varies are shown in Fig. 7. As permeability contrast increases, the total recovery percent decreases, while apparent mobility contrast between two layers intensifies. For reservoir with interlayer permeability contrast of 5, the apparent mobility contrast at $90 \%$ total water cut reached 90 . This demonstrates that apparent mobility could represent interlayer differences at the late development period in low-permeability reservoir. 
Fig. 6 Expanded multiples of average permeability

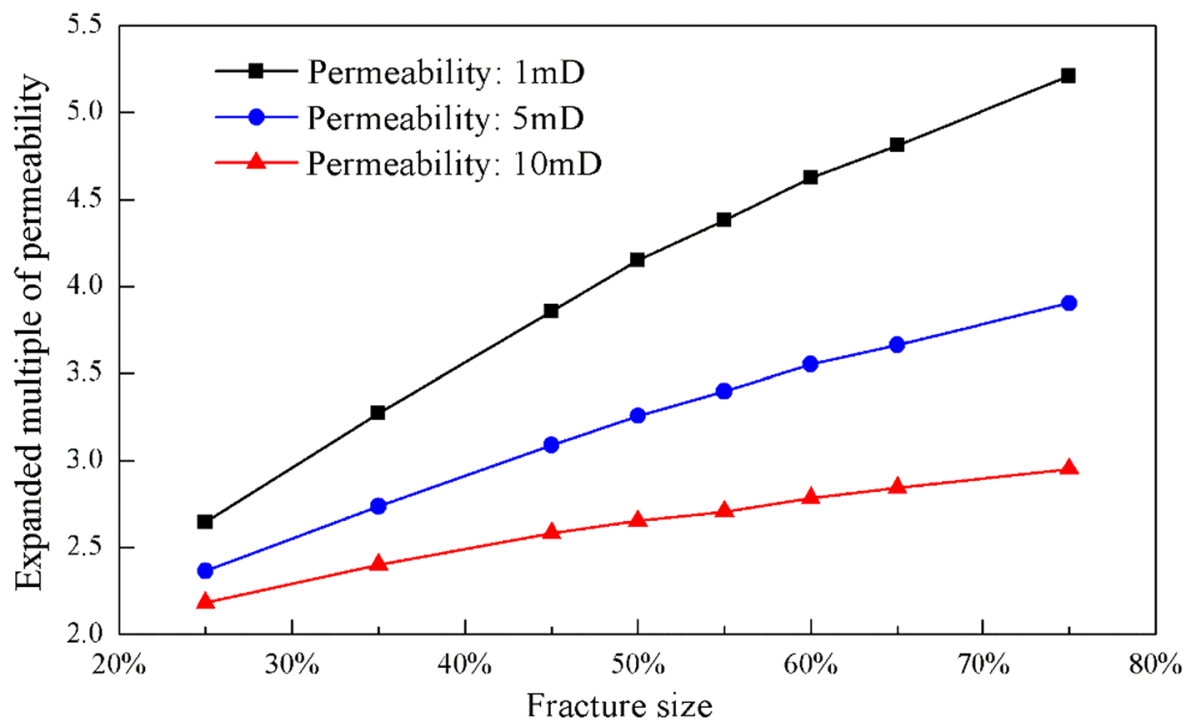

Fig. 7 Interlayer apparent mobility contrast at different permeability contrast

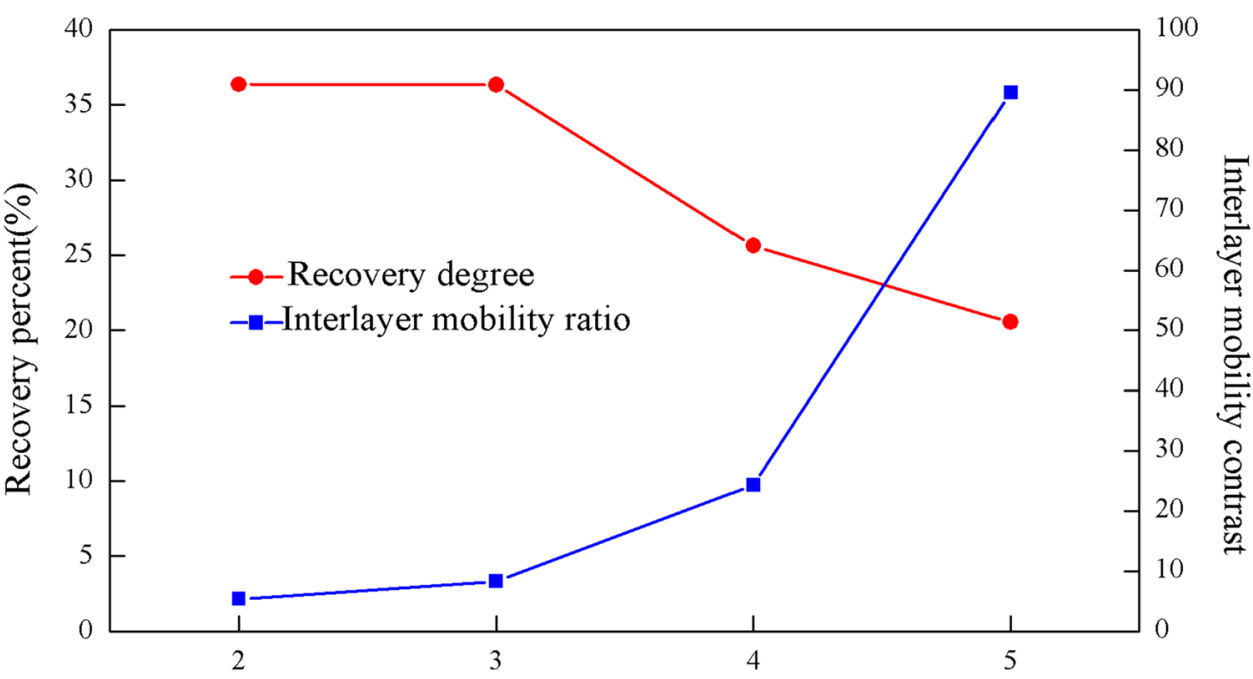

Interlayer permeability contrast

\section{Policy limits of layer recombination}

A multilayer commingling model was established. Coinjection and commingling were employed firstly. Layer recombination was implemented after the reservoir entered into high water cut period.

\section{Model establishment}

A model containing 20 single layers was established. Permeability of single layers increases from upper to bottom, ranging from 5 to $100 \times 10^{-3} \mu \mathrm{m}^{2}$. Other parameters of the model include producer-injector spacing $(200 \mathrm{~m})$, porosity (0.2), reservoir thickness of each layer $(3 \mathrm{~m})$ and crude oil viscosity (1.0 $\mathrm{mPa}$ s). Co-injection and commingling were employed firstly, and layer recombination was implemented when the total water cut reached $90 \%$. Apparent mobility of all single layers at $90 \%$ water cut was calculated. Any two layers with different apparent mobility were combined into a set of new development unit. This new development unit was produced until the total water cut reached $98 \%$.

Recovery percent of all the new different development units at $90 \%$ water cut under $15 \mathrm{MPa}$ producing pressure drop is shown in Fig. 8. As apparent mobility contrast of two layers increases, recovery percent decreases slowly. Such decrease accelerates when the apparent mobility contrast exceeded 3.0. This implies that there is serious interlayer inference in the new development unit, which intensifies difference of recovery percent between two layers. Therefore, under $15 \mathrm{MPa}$ producing 
Fig. 8 Relation between recovery percent and interlayer apparent mobility contrast

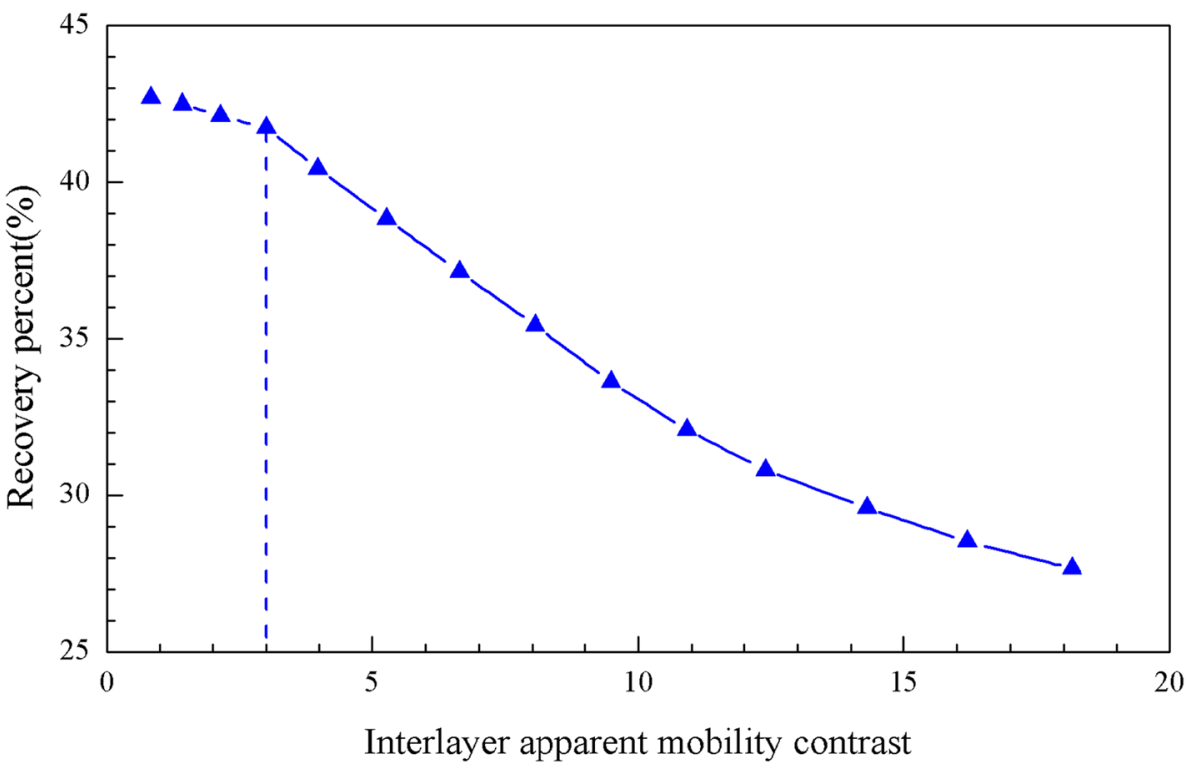

pressure drop, keeping apparent mobility contrast within 3.0 is the policy limit for layer recombination of this low-permeability reservoir at $90 \%$ water cut.

Limit of apparent mobility contrast for layer recombination under different producing pressure drop was determined through above-mentioned method (Fig. 9). As producing pressure drop increases, limit of apparent mobility contrast increases gradually. They present a good logarithmic correlation.

The expression is as follows:

$M_{c}=2.1097 \operatorname{Ln}(\Delta p)-2.7387$
Equation (6) is gained by using reservoir parameters of Block Five of Bonan in Shengli oilfield. It may be different when reservoir parameters changed.

\section{Case study}

Block Five of Bonan in Shengli oilfield is a typical lowpermeability reservoir, showing a mean permeability of $25.5 \times 10^{-3} \mu^{2}$ and $1.0 \mathrm{mPa}$ s crude oil viscosity. It includes eight layers: $1,4,6,8,9^{1}, 9^{2}, 9^{3}$ and $9^{4}$. It received formation test and production test in 1973 and started water flooding in 1976. Eight layers were co-exploited. Now, the recovery percent is $28.2 \%$ and the total water cut is $91.9 \%$. Different layers have significantly different recovery degrees.
Fig. 9 Relation between limit of apparent mobility contrast and producing pressure drop

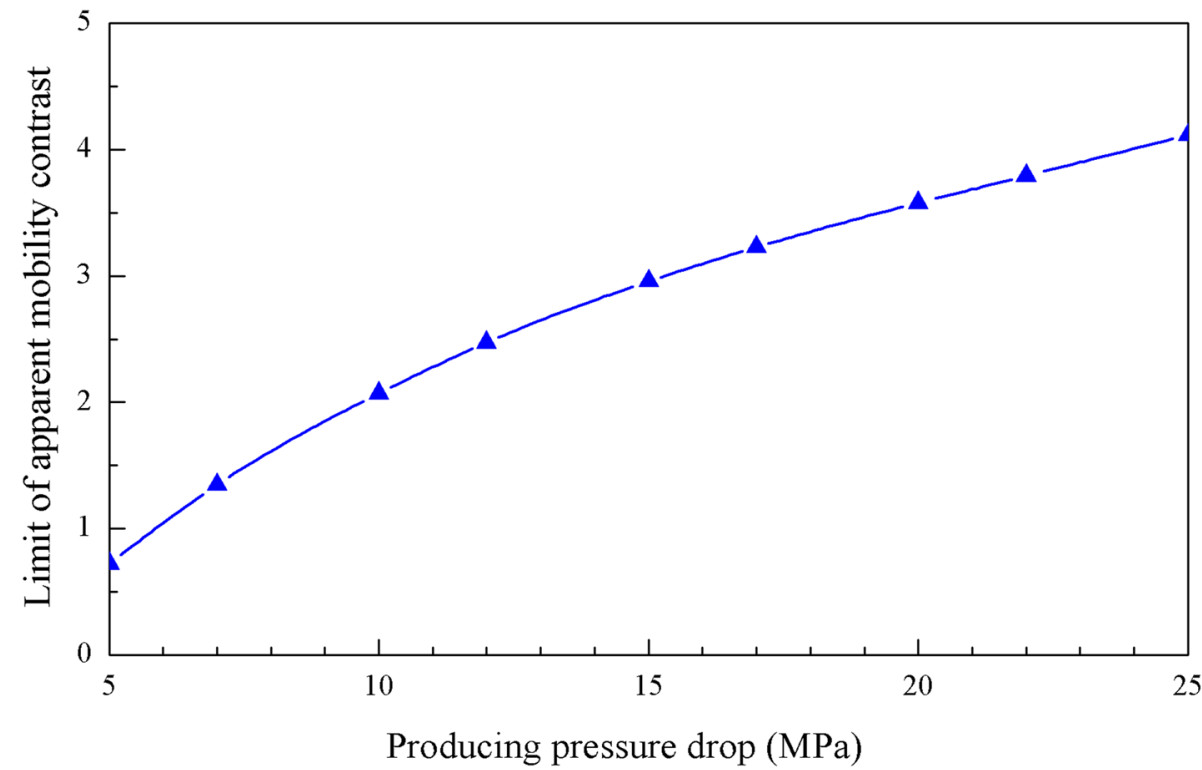

Producing pressure drop (MPa) 
Table 1 Parameters of Block Five of Bonan oilfield

\begin{tabular}{llllll}
\hline Layers name & $\begin{array}{l}\text { Permeability } \\
\left(10^{-3} \times \mu \mathrm{m}^{2}\right)\end{array}$ & $\begin{array}{l}\text { Recovery } \\
\text { percent }\end{array}$ & Oil saturation & $\begin{array}{l}\text { Crude oil vis- } \\
\text { cosity }(\mathrm{mPa} \mathrm{s})\end{array}$ & $\begin{array}{l}\text { Apparent mobility } \\
\left(10^{-3} \times \mu \mathrm{m}^{2} / \mathrm{mPa} \mathrm{s}^{2}\right)\end{array}$ \\
\hline Layer 1 & 64.8 & 0.37 & 0.373 & 0.9 & 22.0 \\
Layer 4 & 43.5 & 0.17 & 0.368 & 1.2 & 12.5 \\
Layer 6 & 36.8 & 0.29 & 0.451 & 1.0 & 18.0 \\
Layer 8 & 12.5 & 0.15 & 0.495 & 0.7 & 11.5 \\
Layer 9 & 19.2 & 0.41 & 0.344 & 0.5 & 6.5 \\
Layer 9 & 11.8 & 0.28 & 0.422 & 0.5 & 8.6 \\
Layer 9 & 8.6 & 0.20 & 0.469 & 0.5 & 9.0 \\
Layer 9 & 9.3 & 0.13 & 0.436 & 0.5 & 7.5 \\
\hline
\end{tabular}

Permeability, recovery percent and the calculated apparent mobility of layers are listed in Table 1.

The producing pressure drop in the study area is about $10 \mathrm{MPa}$. Limit of apparent mobility contrast during layer recombination was 2.2 from formula (6). On this basis, layers were recombined. It could be divided into two sets of layer series of development: (1) Layers 1, 4, 6 and 8 form one set of layer series of development, presenting an apparent mobility contrast of 1.913; (2) Layers $9^{1}, 9^{2}, 9^{3}$ and $9^{4}$ form another set of layer series of development, having an apparent mobility contrast of 1.385 . It also could be divided into three sets of layer series of development: (1) Layers 1 and 6 form one set of layer series of development, with an apparent mobility contrast of 1.222; (2) Layers 4 and 8 form one set of layer series of development, with an apparent mobility contrast of 1.087 ; (3) Layers $9^{1}, 9^{2}, 9^{3}$ and $9^{4}$ are one set of layer series of development. Apparently, it is easy and simple to make layer recombination according to the apparent mobility.

Based on the above layer recombination schemes, production indexes of recombined layer series of development were predicted through numerical reservoir simulation (Fig. 10). At initial stage of production after layer recombination, the water cut decreases firstly and then increases gradually. The development effect is improved significantly after layer recombination. At $98 \%$ water cut, layer recombination with two sets of layer series of development increases recovery percent by $1.1 \%$ and layer recombination with three sets of layer series of development increases by $3.1 \%$. This confirms that layer recombination could contribute better development effect.
Fig. 10 Curves of water cut and recovery percent of reserves

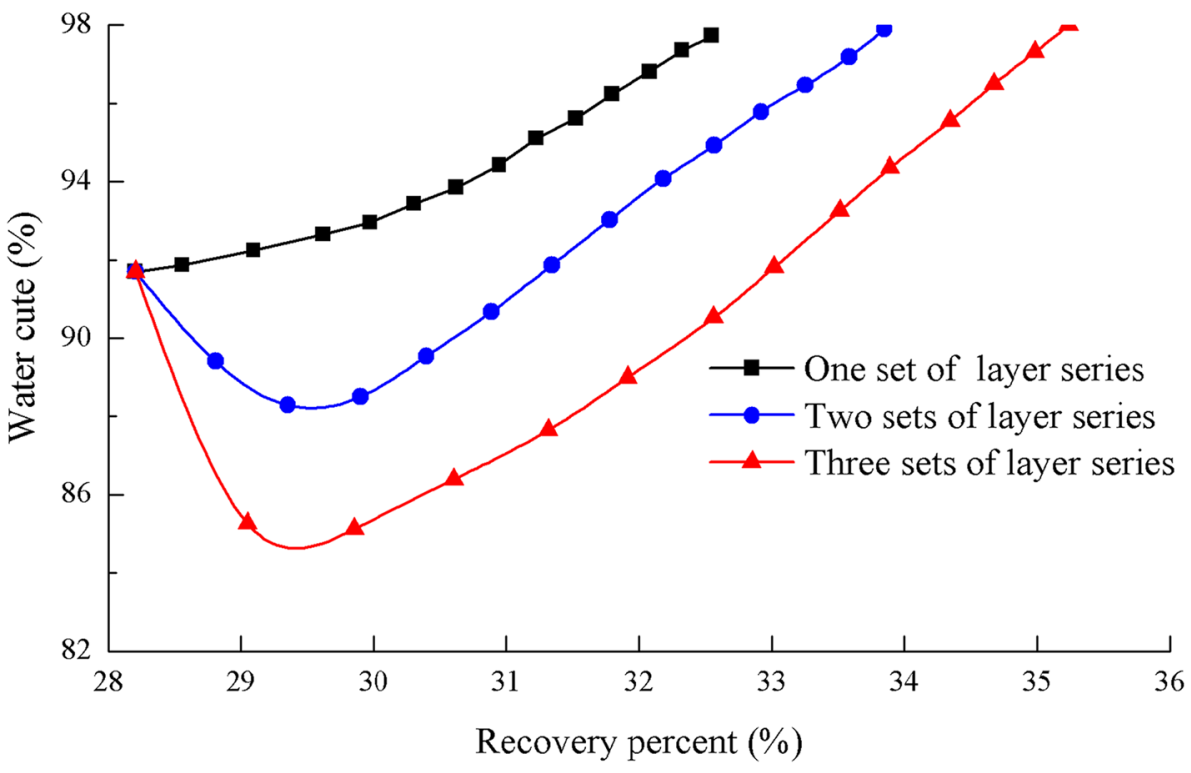




\section{Conclusions}

(1) Permeability, crude oil viscosity, oil saturation and artificial fractures of single layers all will affect layer recombination. It is difficult to consider these influencing factors when making layer recombination. Therefore, this paper proposed interlayer apparent mobility contrast as decision index of layer recombination for low-permeability reservoir at high water cut.

(2) According to the equivalency principle, a calculation chart of equivalent permeability for different hydraulic fracture permeability and sizes implemented in lowpermeability layers is created. The larger the size of the hydraulic fracture and the lower the layers' permeability will be, the larger will be the expanded multiple of permeability after fracturing. This equivalent permeability is introduced into the apparent mobility index; thus, the effect of artificial fractures on layer recombination is being taken into account.

(3) Limit of apparent mobility contrast for layer recombination under different producing pressure drop is determined. It increases with the increase in producing pressure drop. Producing pressure drop in Block Five of Bonan oilfield is about $10 \mathrm{MPa}$, and the corresponding limit of interlayer apparent mobility contrast within one same sets of layer series of development is 2.2. On this basis, layers in Block Five of Bonan oilfield are recombined. Development indexes after layer recombination are predicted. Recovery percent of layer recombination with three sets of layer series of development increases by $3.1 \%$, thus confirming validity of the proposed method.

Acknowledgements This work was supported by National Science and Technology Major Projects (Grant No: 2016ZX05010-002 and Grant No: 2016ZX05011-002).

Open Access This article is distributed under the terms of the Creative Commons Attribution 4.0 International License (http://creativeco mmons.org/licenses/by/4.0/), which permits unrestricted use, distribution, and reproduction in any medium, provided you give appropriate credit to the original author(s) and the source, provide a link to the Creative Commons license, and indicate if changes were made.

\section{References}

Chen MF, Jiang HQ, Zeng YX (2007) A study on max/min permeability ratio boundary for reasonable developed-layer recombination in extremely heterogeneous reservoirs. China Offshore Oil Gas 19(5):319-322

Cui CZ, Zhao XY (2010) Method for calculating production indices of multilayer water drive reservoirs. J Pet Sci Eng 75(1):66-70

Cui CZ, Xu JP, Wang DP et al (2016) Layer regrouping for waterflooded commingled reservoirs at a high water-cut stage. Pet Sci 13(2):272-279

Ehlig-Economides CA, Joseph J (1987) A new test for determination of individual layer properties in a multilayered reservoir. SPE Form Eval (SPE14167) 2(3):261-283

Fu BZ, Kong XT, Chen ZM et al (2002) Principles for combining series of strata in polymer flooding in Lamadian-Saertu-Xingshugang oilfields. Pet Geol Oilfield Dev Daqing 21(6):51-54

Hu DD, Tang W, Chang YW, et al. (2010) A study for redevelopment trends after polymer flooding and its field application in La-saxing oilfield. In: International oil and gas conference and exhibition in China, 8-10 June 2010, Beijing, China. (SPE 130903)

Jackson RR, Banerjee R (2000) Advances in multilayer reservoir testing and analysis using numerical well testing and reservoir simulation. In: SPE annual technical conference and exhibition, 1-4 Oct 2000, Dallas, Texas. (SPE62917)

Liu YP, Chen YM, Yuan SB et al (2007) Well pattern reconstruction of refined cyclothem in the 8th member of Es3 in fault block Tuo21. J Oil Gas Technol 29(5):116-120

Shi CF, Du QL, Zhu LH, et al. (2006) Research on remaining oil distribution and further development methods for different kinds of oil layers in Daqing oilfield at high water-cut stage. In: SPE Asia Pacific oil \& gas conference and exhibition, 11-13 Sept 2006, Adelaide, Australia. (SPE101034)

Wang SB, Niu SW (2004) Layer subdivision in the late high water cut stage in the complex fault block reservoirs, Dongxin oilfield. Pet Explor Dev 31(3):116-118

Wang QC, Wang X, Ren JB et al (2007) The layer system subdivision development technology of Anan low permeability sandstone reservoir. Henan Pet 15(6):31-33

Yu HJ (2010) The division and combination of series of development strata in Chunhua low-permeability Oilfield with thin inter-beds. Complex Hydrocarb Reserv 3(1):58-61

Zhang SM, Liu ZH, Wan HY et al (2005) Technical limits for pattern rearrangement in late period of high water-cut in uncompartmentalized oilfield. Spec Oil Gas Reserv 12(2):57-62

Publisher's Note Springer Nature remains neutral with regard to jurisdictional claims in published maps and institutional affiliations. 